\title{
IMPASSES ÉTICOS NA EDUCAÇÃO HOJE
}

\author{
Luiz A. Calmon Nabuco Lastória* \\ (...) pertence à moral não se sentir em casa em sua \\ própria casa. (...) Não há vida correta na falsa. \\ T. W. Adorno (Minima moralia)
}

\begin{abstract}
RESUMO: O presente artigo trata da consciência filosófica expressa nas formulaçôes de T. W. Adorno quanto ao desvanecimento da ética como possibilidade inerente ao ato educativo. Tendo em vista compreender o significado do termo "doutrina da vida reta" que, nas palavras de Adorno, teria caído em esquecimento na atualidade, o presente texto revisita o pensamento ético de Aristóteles, procurando elucidar o seu sentido imanente à educação. Por fim, extrairemos desse percurso algumas preocupações referentes ao problema da educação contemporânea sob a ótica das formulações de Adorno.
\end{abstract}

Palavras-chave: Ética. Educação. Aristóteles. Adorno. Família.

\section{ETHICAL IMPASSES IN EDUCATION TODAY}

ABSTRACT: This paper deals with the philosophical conscience in the thinking of T. W. Adorno as for the fading of ethics as an inherent possibility for education. In attempt to understand the meaning of the "doctrine of the mean", which, according to Adorno, would have currently been forgotten, this article revisits the ethical thinking of Aristotle, trying clarify its immanent meaning to education. Finally, some issues about contemporary education matters are discussed under the perspective of the thoughts of Adorno.

Key words: Ethics. Education. Aristotle. Adorno. Family.

Professor Dr. da Faculdade de Ciências Humanas e membro do Grupo de Estudos e Pesquisa "Teoria Crítica e Educação", do PPGE da Universidade Metodista de Piracicaba (UNIMEP).E-mail: lacalmon@unimep.br

Educ. Soc., Campinas, vol. 24, n. 83, p. 429-440, agosto 2003

Disponível em <http://www.cedes.unicamp.br> 


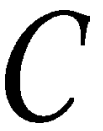

omo é sabido, a educação foi compreendida pelos gregos antigos como um tipo de artesanato por meio do qual tanto o corpo como o espírito humanos deveriam ser esculpidos, visando a realizar a perfeição de suas formas próprias. W. Jaeger, referindo-se aos propósitos da educação no seio da paidéia grega, sublinhou que: "A mais alta obra de arte que o seu anelo se propôs foi a criação do homem vivo" (Jaeger, 1989, p. 9). À educação do corpo cabia, segundo as idades e as atividades a se realizar, a prescrição correta de exercícios físicos (ginástica) e também dos alimentos adequados a serem ingeridos (dieta). Já à educação do espírito convinha habituar as crianças, desde a mais tenra idade, aos valores mais elevados cultivados pela vida em comunidade na polis. Desse modo, o tema da ética articulara-se de forma imanente, sobretudo a partir da sofística tardia, como veremos, ao ato educativo.

Com Aristóteles, a ética deixará de ser vista como uma ontologia do Bem, tal como Platão a concebera, adquirindo então o estatuto de uma disciplina própria com aplicação prática: praktiké episthéme. O imperativo socrático segundo o qual é necessário conhecer o que é o Bem, para que, desse modo, possamos tornarmo-nos melhores com relação àquilo que já somos, adquire em Aristóteles a feição de uma "doutrina da vida reta". E é nestes termos que T. W. Adorno se referiu, já no parágrafo que abre a dedicatória da Minima moralia endereçada ao seu amigo M. Horkheimer, à "triste ciência" que, em nossos dias, "caiu em esquecimento". Mas, antes de nos determos na compreensão do sentido dessas poucas palavras que expressam o ponto de vista de Adorno sobre as pretensas filosofias morais ou as éticas, que versam sobre o ethos cultural contemporâneo, vejamos com mais vagar como os motivos conceituais da ética se articularam de modo imanente ao plano da educação.

Aristóteles inicia a sua Ética a Nicômacos considerando esse tipo de investigação como parte da ciência política. Parte da simples constatação de que todas as atividades visam a algum fim: a saúde é considerada como o fim da medicina, a nau como o fim da engenharia naval e a riqueza como o fim da economia. Esse fim para o qual todas as coisas tendem é via de regra considerado um bem. Tendo em vista, porém, que as atividades nas quais os homens se empenham são múltiplas, as finalidades (bens) correspondentes a estas também o são. Além do mais, Aristóteles argumenta que: 
(...) aunque el bien del individuo se identifique con el bien del estado, parece mucho más importante y más conforme a los fines verdaderos llevar entre manos y salvar el bien del estado. El bien es ciertamente deseable cuando interesa a un solo individuo; pero se reviste de un carácter más bello y más divino cuando interesa a un pueblo y a unas ciudades. A esto va, pues, nuestro tratado presente, que es, de alguna manera, un tratado de la ciencia política. (Aristóteles, 1982, p. 273)

Isso posto, Aristóteles desenvolve seu argumento procurando estabelecer uma relação de subordinação entre as diversas finalidades e interroga-se sobre haver uma finalidade última e, portanto, mais perfeita, que pudesse ser desejada por si mesma. Já nesse momento da reflexão empreendida pelo filósofo, a política aparecerá como a mais arquitetônica de todas as ciências; isso na medida em que cabe à política subordinar todos os outros fins particulares às demais artes ou ciências (economia, retórica, estratégia militar etc.). É também a política que determina quais as ciências que devem ser estudadas numa cidade, por quem e até que ponto.

Visto que a ética pertence ao campo da política, o fim almejado por este tipo particular de conhecimento visa, igualmente, àquela no âmbito da ação humana. Mas qual seria a finalidade da ciência política e o mais alto de todos os bens a que pode levar a ação humana? A felicidade da alma, ou eudaimonía, responde o filósofo em consonância com o pensamento corrente de sua época. Somente a felicidade pôde ser considerada pelos gregos aquela finalidade última e perfeita (ou Bem Supremo) que desejamos em si e por causa de si mesma ou, como argumentou Aristóteles, aquela finalidade que não pode mais ser convertida em meio para que se alcance uma outra que lhe sobrevenha. Portanto, sendo a felicidade um fim último para a existência humana, Aristóteles, ao polemizar com a perspectiva platônica, objetará que a felicidade se realiza somente por intermédio do conjunto de finalidades tangíveis ao homem como meios realizáveis. Os homens escolhem os prazeres, as honras e outras coisas que consideram bens pensando que, por meio deles, serão felizes.

No catálogo dos bens tangíveis aos homens, somente a felicidade constituirá o bem mais elevado pertencente aos chamados bens da alma. E isso significa, em primeiro lugar, que se trata de um bem próprio ao homem e não de um bem pertencente à classe dos bens que lhe são exteriores. Diferentemente da riqueza que pertence a esta última classe de bens e das honrarias que dependem 
também daqueles que as concedem para além daqueles que as recebem, a felicidade tem abrigo no próprio indivíduo, realiza-se somente por meio de suas ações e não lhe pode ser facilmente subtraída.

Ademais, esse Bem Supremo próprio ao homem só poderá ser realizado sob a forma de uma atividade conforme a excelência, nos diz Aristóteles. Ou seja, dado que só a alma humana é dotada de razão, diferentemente dos demais seres vivos, o bem para o homem só poderá advir do exercício ativo e contínuo das faculdades racionais da alma. De forma análoga ao tocador de cítara que qualificamos como um "bom" citarista se ele executar bem a sua atividade de tocar cítara, também o homem poderá ser chamado de um bom homem se ele executar de maneira excelente tais faculdades racionais da alma durante a sua vida. Aristóteles compreende ainda que a vida ativa, conforme a excelência, deve ser agradável em si mesma. Somente o amante da excelência pode se sentir atraído e se comprazer com os atos considerados excelentes, dispensando assim outras formas postiças de prazer que lhe poderiam ser também agradáveis, embora não por sua própria natureza. E, nessa medida, os atos executados com perfeiçãao por aquele que age e se compraz em sua ação são, ao mesmo tempo, os bons atos e os mais belos atos. Comprazer-se com tais atos equivale, segundo Aristóteles, a ser feliz.

Ainda que o filósofo defina a felicidade tal como a descrevemos acima, ele ressalta que para a sua realização também são necessários bens exteriores como pré-requisitos, uma vez que é impossível ou, na melhor das hipóteses, é muito difícil praticar boas e belas ações sem as condições e os instrumentos necessários e apropriados. E será também neste sentido que a finalidade suprema da política, a atividade que comanda o conjunto de fins-meios para a realização última do homem por intermédio da polis, aparecer-lhe-á como sendo a de infundir um certo caráter nos cidadãos de forma que se tornem bons e, portanto, capazes de praticar boas ações. Mas isso quer dizer tão-somente que a felicidade, como atividade racional, não poderá realizar-se fora do âmbito da polis sob um bom governo.

Entretanto, como bem nos adverte Samaranch, em seu comentário sobre esse assunto, "no hay Política sin una psicología de base” (Aristóteles, 1982, p. 295). Além do mais, não devemos nos esquecer de que a matéria em exame pelo filósofo é a felicidade do homem concreto diante de todas as vicissitudes que, porventura, recaiam sobre a sua vida. Por esse motivo, a idéia de felicidade deve 
estar em concordância com a imagem segundo a qual uma pessoa "supinamente feliz" ou tenazmente virtuosa será aquela capaz de suportar com dignidade e grandeza todos os tipos de infortúnios próprios à condição humana, sem com isso se deixar deslocar facilmente desse "porto seguro" que é a sua felicidade conquistada pelo esforço próprio.

Visto que a felicidade consiste numa certa atividade da alma conforme a excelência e que a política pressupõe também uma psicologia para bem se realizar, razão por que o estadista deve compreender a alma humana para melhor realizar os seus intentos, Aristóteles passa então ao exame da excelência em conformidade com as partes que estruturam a alma (psyché). Em seu tratado Da alma, esta aparece como sendo constituída por duas partes básicas e comunicáveis entre si: uma parte irracional (álogon) e outra parte dotada de razão (logos). A primeira compreende uma subparte responsável pelas funções de natureza vegetativa - como a nutrição e o crescimento -, comum aos demais seres vivos, e uma outra subparte que, embora "privada de razão", mostra-se sensível aos seus apelos. Já a segunda parte da alma (o logos) compreende tanto a chamada "alma desperta" - donde provêm as virtudes que ouvem a razão - como o logos propriamente dito.

Tendo em vista ambas as partes que compóem a alma humana, Aristóteles concebeu duas classes de excelências (ou virtudes) correspondentes àquelas: as virtudes dianoéticas, que procedem da parte racional da alma e visam ao aprimoramento de nossas capacidades intelectuais (como a inteligência e o discernimento, por exemplo); e as virtudes éticas (tais como a moderação e a liberalidade) que, embora procedam da parte racional ("alma desperta”), objetivam aquela parte inconsciente - porém sensível aos apelos da razão -, onde se situam fundamentalmente as diversas emoções (páthe) e também o desejo (órexis). Ao passo que as virtudes dianoéticas se desenvolvem nos indivíduos por intermédio da instrução - e por isso requerem experiência e tempo -, as virtudes éticas são o produto dos hábitos. E aqui o filósofo evidencia o elevado papel da educação na formação individual.

Os hábitos (hexis), por sua vez, são forjados pela prática contínua de determinadas ações que são transmitidas ao educando por meio de exemplos, máximas populares, castigos, exortaçôes etc. Logo, pode-se dizer que o exercício contínuo das mesmas açóes termina por fixar no indivíduo certas disposições. São essas disposi- 
ções, geradas por intermédio dos processos educativos, que qualificarão, posteriormente, o seu agir em termos de virtudes ou vícios, conformando assim o caráter individual. Os hábitos são, portanto, potências determinadas que se fixam no indivíduo mediante o caráter repetitivo dos atos, predispondo-o, dessa maneira, a certas formas de agir, o que por sua vez incidirá novamente sobre essas mesmas potências. A esse respeito nos diz Aristóteles:

É evidente, portanto, que nenhuma das várias formas de excelência moral se constitui em nós por natureza, pois nada do que existe por natureza pode ser alterado pelo hábito. Por exemplo, a pedra, que por natureza se move para baixo, não pode ser habituada a mover-se para cima, ainda que alguém tente habituá-la jogando-a dez mil vezes para cima; tampouco o fogo pode ser habituado a mover-se para baixo, nem qualquer outra coisa que por natureza se comporta de certa maneira pode ser habituada a comportar-se de maneira diferente. Portanto, nem por natureza nem contrariamente à natureza a excelência moral é engendrada em nós, mas a natureza nos dá a capacidade de recebê-la, e esta capacidade se aperfeiçoa com o hábito. (Aristóteles, 1992, p. 35)

Eis por que, segundo Aristóteles, uma educação exemplar desde a mais tenra infância torna-se decisiva para a constituição do caráter dos indivíduos em termos de excelência e, mais tarde, tornar-se-á igualmente decisiva para a práxis política virtuosa no âmbito da cidade. Mas uma tal educação exemplar também supõe, por sua vez, uma comunidade política já excelente. Ou, dito de outro modo, o ideal de uma vida ética pressupóe ao menos um ethos coeso, ordenado e relativamente estável. Nessa direção, Heller (1987) observou que Aristóteles se deu conta de que não apenas as tragédias continham elementos insuperáveis para a sua filosofia moral como também todo o grandioso passado ateniense determinara, em grande medida, a elaboração conceitual do seu pensamento.

A ação virtuosa será ainda, segundo Aristóteles, uma ação de acordo com a "reta razão". Esse princípio geral, adotado pelo filósofo e que será esclarecido mais adiante, aplica-se a todos os casos particulares, partindo-se da premissa segundo a qual as açôes virtuosas engendradas pela educação são destruídas pelo excesso e pela falta. De acordo com essa premissa, a reta razão deverá buscar atingir o ponto médio (mesótes) entre os dois extremos viciosos.

Com as disposições morais da alma passa-se o mesmo que com as disposições do corpo, argumenta o filósofo. Assim como a saúde e o vigor são prejudicados pela ingestão excessiva ou insuficiente de 
alimentos e pela prática incorreta de exercícios físicos, a coragem é prejudicada por aquele que teme e evita todas as coisas, tornando-se assim um covarde, ou por aquele que nada teme e, dessa forma, torna-se um temerário. Aristóteles toma os prazeres ou sofrimentos supervenientes às açóes de um indivíduo como indícios de suas disposições morais. Neste sentido, somente os indivíduos capazes de se alegrarem por se absterem de uma entrega desmedida aos prazeres do corpo ou de não sofrerem no enfrentamento de coisas temíveis, por exemplo, podem realmente ser tidos como virtuosos.

Visto que as ações de um indivíduo que se conduz pela reta razão devem objetivar o ponto médio entre os extremos viciosos em toda e qualquer situação particular, e visto que esse exercício pressupóe o autocontrole dos nossos sentimentos, podemos supor que Aristóteles esboça o seu pensamento ético à moda de uma "terapêutica", por meio da qual se busca conquistar a "saúde da alma", de forma análoga à medicina que visa à saúde do corpo. E, conforme o "receituário" prescrito por essa ética, o indivíduo deverá reconhecer, em primeiro lugar, as próprias fraquezas mediante a observação dos prazeres e sofrimentos que experimenta, uma vez que é em função delas que nos inclinamos, freqüentemente, aos erros. Em segundo lugar, o indivíduo deve procurar dirigir-se resolutamente para o extremo oposto àquele em que se reconhece como fraco, pois somente dessa forma conquistará a posição intermediária almejada, afastandose tanto quanto possível do erro para o qual tende a inclinar-se.

Nessa "terapêutica da alma", concebida em termos sociopolíticos de tipo comunitário, tanto a educação familiar quanto as leis da cidade se completam em nível do ethos, a fim de possibilitar a conversão dos costumes em hábitos e, destes últimos, em ações virtuosas segundo o ideal de uma vida ética, cujo valor supremo é alcançar a felicidade da alma. Aristóteles também sabia que para o homem é mais difícil lutar contra o prazer que contra a própria cólera, razão pela qual argumentou em favor de que os indivíduos eticamente virtuosos deveriam saber exercer o difícil controle sobre as próprias paixões e apetites. Não se trata de renunciar às paixões, como bem observou G. Lebrun, pois nesse caso seria impossível supormos uma escala de valores éticos, mas ao contrário disso, de saber temperá-las, ou melhor, de saber dosar quanto de passionalidade cada ato individual comporta inevitavelmente.

Após termos acompanhado Aristóteles até esse ponto, podemos compreender melhor a sua definição genérica de exce- 
lência moral segundo a qual tal excelência se constitui numa “(...) disposição da alma relacionada com a escolha de ações e emoções, disposição essa consistente num meio-termo (o meio-termo relativo a nós) determinado pela razão (a razão graças à qual um homem dotado de discernimento o determinaria)" (Aristóteles, 1992, p. 42).

Mas ainda que um indivíduo procure orientar-se pelo termo médio com relação a si mesmo entre os extremos igualmente viciosos (o do excesso e o da falta), nas diferentes circunstâncias com as quais se depara e tal como o determina a reta razão, resta-nos saber no que consiste mais especificamente esta última. Conforme já mencionamos, cada uma das partes que compóem a alma humana se subdivide em duas outras. Quanto à parte racional, Aristóteles distingue a faculdade que nos permite contemplar as coisas cujos princípios são invariáveis e outra que nos permite contemplar as coisas passíveis de variação (e por isso mesmo impossíveis de serem demonstradas). A primeira aplica-se aos raciocínios próprios às chamadas ciências teóricas (aquelas que procuram alcançar a verdade última do ser das coisas) e a segunda aplica-se às matérias práticas e contingenciais, que se apresentam a nós como objeto de deliberação (o que por sua vez exige uma atitude calculativa).

Uma vez que a faculdade da parte racional da alma que se volta para as coisas variáveis é a mesma que intervém em nossas escolhas e uma vez que essas escolhas nada mais são que o desejo deliberado, segue-se que, para realizarmos uma boa escolha, tanto a razão deverá ser verdadeira (correta) quanto o desejo deverá estar em conformidade com ela. Por esse motivo, Aristóteles é bastante claro ao afirmar que:

Este tipo de pensamento e percepção da verdade é de natureza prática; quanto ao pensamento contemplativo, que não é nem prático nem produtivo, o bom e o mau funcionamento são respectivamente a percepção da verdade e a impressão da falsidade; com efeito, essa é a função de toda a parte intelectual do homem, enquanto o bom funcionamento da inteligência prática é a percepção da verdade conforme ao desejo correto. (Aristóteles, 1992, p. 114)

Logo, a origem de uma ação reside na escolha e esta, por sua vez, possui o desejo como a sua causa eficiente. E, sendo assim, as boas e más ações exigem necessariamente a combinação de um certo tipo de pensamento racional com o caráter do agente. Portanto, o exercício de uma conduta orientada pela reta razão (orthòs lógos), 
tendo em vista o estabelecimento da medida justa apropriada para pautar as virtudes éticas do indivíduo, implicará o desenvolvimento de uma sabedoria de tipo prático (ou phrónesis). E esta será, pois, considerada por Aristóteles a virtude dianoética fundamental correspondente à parte racional calculadora da psyché (tò logistikón) - para exercer o comando da vida no sentido prescrito pela reflexão ética acerca do bem (agathón) próprio ao homem.

Pois bem, expusemos até aqui alguns dos principais motivos conceituais que constituíram a chamada "doutrina da vida reta" de perfil comunitário, tal como esta fora pensada por Aristóteles. Entre esses motivos figura o destacado papel da educação como prática mediadora de valores, orientada para a formação daqueles bons hábitos imprescindíveis à conduta virtuosa dos cidadãos no interior da polis. Diante do exposto devemos, então, ler no tom de lamento contido nas palavras de Adorno, mencionadas no início, menos uma adesão a um suposto teor de verdade expresso por uma doutrina não mais em vigência na atualidade, e mais o indicativo de uma possibilidade histórica que o pensamento filosófico, ao seu ver, efetivamente perdera: a de ocupar-se com o tema da "vida reta". Se ainda existem filosofias morais que insistem nessa tarefa após Auschwitz, elas já não são mais dignas desse nome, uma vez que a promessa de uma vida melhor mediante o emprego da razão se tornou absolutamente insustentável. Mas, tal como para Freud a loucura contém a chave para a compreensão da "normalidade", também Auschwitz representa, na perspectiva de Adorno, o paradeiro da racionalidade operante nas sociedades contemporâneas ditas esclarecidas.

Se a possibilidade de levarmos uma vida "correta" ou justa escapa aos nossos horizontes concretos no presente, é porque a totalidade social, sobretudo no seu âmbito axiológico e normativo, vem se concretizando sob a égide da grande indústria da cultura de modo cada vez mais totalitário. Ao fascismo como fenômeno político de Estado, sucede o fascismo cultural que permeia a vida cotidiana das sociedades capitalistas em tempos "normais". Portanto, como situar o télos ético das práticas educativas, em sentido aristotélico, à luz desse diagnóstico?

Longe de fornecer uma resposta minimamente satisfatória a essa questão, podemos extrair do pensamento de Adorno apenas algumas poucas preocupações relacionadas com o tema, que, embora sejam absolutamente insuficientes para estancar o processo 
de barbarização crescente no qual se acham imersos os indivíduos e grupos sociais na contemporaneidade, são, em contrapartida, imprescindíveis aos atos educativos. Entre essas preocupações consta que os educadores devem ter presente o processo de obsolescência da instituição família imposta pela fase atual do capitalismo. Afinal, a família como instituição responsável pela formação dos hábitos na criança, conforme uma hierarquia clara e distinta de valores sociais defensáveis em nível do sensus communis, do ponto de vista ético, cedeu à cultura mediática e à "educação terceirizada" em suas mais diversas formas (babás, creches, préescolas etc.). De outro lado, o desmantelamento das instituiçôes públicas operado pelas políticas de âmbito nacional, em conformidade com os ditames econômicos decorrentes da chamada "globalização", particularmente dos estabelecimentos públicos de ensino, vem agravar enormemente a difícil tarefa reservada aos educadores no âmbito formal nos dias atuais.

Já no que diz respeito ao ato educativo propriamente dito, isto é, à díade educador-educando, Adorno alerta-nos para pelo menos dois aspectos bastante delicados de cunhos psicológico e histórico, a um só tempo. O primeiro aponta para a imprescindibilidade da reflexão acerca dos fatores irracionais inerentes ao ato educativo por parte dos atores nele envolvidos. Este aspecto nos coloca diante da difícil tarefa de elaboração do medo numa sociedade que deve, em grande medida, sua coesão justamente a esse tipo de sentimento. Vale a pena mencionar aqui o que Adorno denomina de "comportamento economicamente racional", isto é, condutas supostamente racionais impostas pela totalidade social mediante as quais os indivíduos abdicam de si mesmos para se conservarem socialmente. Nas sociedades regidas pelo equivalente universal de troca, a imagem que a consciência individual forma do "eu" está mediada pela perspectiva do "bom negócio". Dado que uma boa imagem pressupõe astúcia no jogo competitivo do mercado - imperativo para a realização de cada um -, expor nossos temores macula nossa "boa imagem" tornando-nos frágeis e, desta sorte, põe em risco a nossa existência. Daí a dificuldade de expor nossos temores, mesmo quando isso é possível ou até mesmo plausível.

O segundo aspecto implica, igualmente, a imprescindibilidade de o ato educativo se contrapor à amnésia social crescente, engendrada pela grande indústria da cultura, de modo que se 
permita tanto a elaboração do passado, tomado no sentido social mais amplo, como a elaboração do passado imediato transcorrido nas relações concretas. Pois, se para o passado não pode haver justiça, o presente necessita ainda ser salvo e, neste sentido, o télos ético dos atos educativos deve constituir-se pela consciência de que não nos devemos nos curvar às atrocidades cometidas no passado como algo que simplesmente já passou, muito menos postular simplesmente a sua superação; dado que esse passado não se apaga, nem é passível de resolução por essa via, continuará clamando por ser reparado. Ignorar esses aspectos equivale a rumar cegamente em direção ao futuro eivado pelas mazelas desse mesmo passado ignorado. $\mathrm{Ou}$, dito de outro modo, ignorar esses aspectos equivale a desfigurar a finalidade ética imanente à educação possível no presente em suas determinações primeiras: ética e política. Não obstante isso, seria ingenuidade supor que a tarefa de elaboração do passado imputada à consciência na educação seria o suficiente para conter o processo de barbarização social em curso, uma vez que, tal como nos faz lembrar Adorno, também os fatores objetivos que engendraram Auschwitz ainda não se alteraram historicamente e continuam se impondo aos indivíduos mediante a irracionalidade institucional do sistema.

De certo cada um desses aspectos, aqui apenas indicados, requer um esforço de elaboração conceitual específico para poder servir como balizas mínimas, ou melhor, como esclarecimento ao exercício da pedagogia nos dias de hoje.

Recebido e aprovado em maio de 2003.

Referências bibliográficas

ADORNO, T.W. Minima moralia. São Paulo: Ática, 1992.

ADORNO, T.W. Educação e emancipação. São Paulo: Paz \& Terra, 1995.

ADORNO, T.W. Actualidad de la filosofia. Barcelona: Paidós/ICE$\mathrm{UAB}, 1991$.

ARENDT, H. A dignidade da politica. Rio de Janeiro: Relume Dumará, 1993. 
ARISTÓTELES. Obras. Madrid: Aguilar, 1982.

ARISTÓTELES. Ética a Nicômacos. Brasília, DF: UnB, 1992.

HELlER, A. Aristóteles y el mundo antiguo. Barcelona: Península, 1987.

JAEGER, W. Paidéia. 2a ed. São Paulo: Martins Fontes, 1989.

LEBRUN, G. O conceito de paixão. In: OS SENTIDOS da paixão. São Paulo: Companhia das Letras, 1991.

NOVAES, A. (Org.). Ética. São Paulo: Companhia das Letras, 1992. 